\title{
Impact of the speech sound disorders: family and child perception
}

\author{
Simone Nicolini de Simoni ${ }^{1}$ \\ https://orcid.org/0000-0002-3764-4171 \\ Iana Caroline Leidow ${ }^{2}$ \\ https://orcid.org/0000-0002-2174-9104 \\ Deisi Luana Britz ${ }^{2}$ \\ https://orcid.org/0000-0003-4815-8192 \\ Denis Altieri de Oliveira Moraes ${ }^{3}$ \\ https://orcid.org/0000-0002-2059-5481 \\ Márcia Keske-Soares ${ }^{4}$ \\ https://orcid.org/0000-0002-5678-8429
}

Universidade Federal de Santa Maria, Programa de Graduação em Distúrbios da Comunicação Humana, Santa Maria Rio Grande do Sul, Brasil.

Universidade Federal de Santa Maria, Santa Maria, Rio Grande do Sul, Brasil. Universidade Federal de Santa Maria, Departamento de Estatística, Santa Maria, Rio Grande do Sul, Brasil.

Universidade Federal de Santa Maria, Departamento de Fonoaudiologia, Santa Maria, Rio Grande do Sul, Brasil.

Article developed at the Speech-Language Pathology and Statistics Department of the Federal University of Santa Maria, Rio Grande do Sul, Brazil.

Conflict of interests: Nonexistent

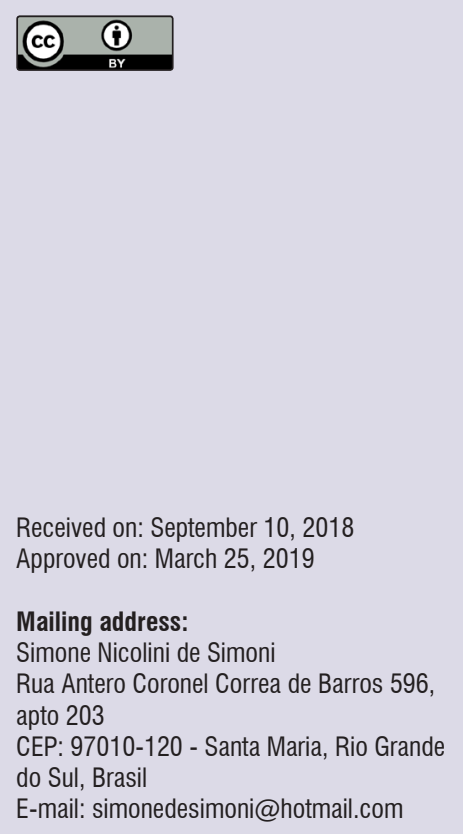

\section{ABSTRACT}

Objective: to verify both the family's and the children's perception of the impact of the phonological type of speech sound disorders.

Methods: this is an exploratory qualitative-quantitative prospective research of a Speech-Language Pathology Service of a Higher Education Institution. Sixty-four persons took part in the study, thirty-two being children (nineteen boys and thirteen girls), their age ranging from four years and one month to eight years and nine months, diagnosed with the phonological type of Speech Sound Disorder. Besides them, thirty-two adults, either their parents or guardians, participated in the study. The results were organized by degree of association - strong association, average association and average association with aspects of speech.

Results: regarding the parents' perception, the impact of Speech Sound Disorder on their children is related to interpersonal relationships and to emotional behavior, besides school issues. As for the children's perception, the results demonstrated that the biggest impact of irregular speech takes place in unfamiliar environments. In addition to that, they have shown that isolation and the development of feelings such as frustration, shyness and low self-esteem are common among these children, making their relationship with other people difficult.

Conclusion: the perception of parents and children regarding speech-related difficulties should be studied in order to reach both a better understanding and a more adequate treatment of Speech Sound Disorders.

Keywords: Speech, Language and Hearing Sciences; Speech Sound Disorder; Communication; Children 


\section{INTRODUCTION}

When children are born, they are included in a communicative environment that will provide the first interactions and exchanges of affection ${ }^{1}$. The concept of communication in the broader health concept involves biological abilities related to mental and social contexts. Thus, considering the typical development and the adequate chronology of children's linguistic components, they should develop the task of receiving, elaborating and transmitting messages of meaningful verbal content. If a child doesn't develop this specific linguistic task, and the degree of irregularity prevails so that it hinders communicative efficiency, there being no affecting organic or chronological issues, it is then defined as a communication disorder ${ }^{2}$.

In regard to oral communication, it is known that the acquisition of oral language takes place gradually - more specifically the phonologic acquisition, in which the speech sounds are acquired. In Brazilian Portuguese (BP), the typical phonologic control - that is, the acquisition of all speech sounds without any incidents - is achieved by the age of five ${ }^{3}$. Throughout the time in which speech sounds are developed, some difficulties might happen, as, for example, substituting one sound for another, omitting a sound, having a hard time articulating, etc ${ }^{4,5}$. Whenever there is a major disparity in the phonologic acquisition in relation to age and to the acquisition of phonemes, the child is said to have Speech Sound Disorder (SSD). Such disorders may be both or either of two conditions: difficulties resulting from a linguistic basis (phonological disorders) and difficulties related to articulation (phonetic disorders) ${ }^{1,6,7}$.

The phonological types of SSD are characteristic, for these children switch sounds when they speak, but don't have evident organic alterations ${ }^{8}$. Such switching occurs during the time of phonologic acquisition, usually between four and eight years old, approximately ${ }^{9}$. The etiology of the phonological types of SSD is still unknown; however, there is a research which presents some influencing factors, such as: gender, age, otitis and auditory issues, respiratory alterations and changes in the family environment ${ }^{10}$. Also, another research points to the fact that being an only child is a risk factor ${ }^{11}$. These data reveal the importance of the initial interview, characterized as an interventional anamnesis, besides the knowledge of the history of each case and the family structure of the child, since some factors may be influencing the child's $\mathrm{SSD}^{7-10}$.
Diagnosis of the phonological type of SSD demands that the professional have previous knowledge of the typical patterns of phonologic acquisition, as well as of the adequate assessing tools to indicate a diagnosis hypothesis. Since the consequences of SSD affect the child as well as the family and those close to them, knowing the parents' and the child's opinion regarding the speech problem also helps in planning and conducting the therapy. However, there is a lack of tools and questionnaires in researches in the field of speech-language pathology which would provide such parents' and children's perception about difficulties in speech $^{5,12}$.

The questionnaire called Speech Participation and Activity Assessment of Children, a.k.a. SPAA-C ${ }^{13}$, is a complementary assessment tool that makes possible to know the impact that SSD causes in the child. It makes use of questions to the child, parents, siblings, friends, teachers and other close acquaintances, mainly seeking for an answer as to how the difficulties caused by this oral communication limitation are faced by them ${ }^{14}$.

The questionnaire was developed in the structures composed by the International Classification of Functioning, Disability and Health: Children and Youth Version (ICF-CY) ${ }^{15}$, which in turn is part of the World Health Organization Family of International Classifications - WHO-FIC. Therefore, it is the universal reference framework adapted by WHO to describe, assess and measure health and inability both on individual and populational level. Besides providing a holistic basis for the understanding of the development of speech, it allows for the improvement of knowledge in other fields of healthcare regarding these impairments, being thus important for the multidisciplinary assessment and treatment ${ }^{13}$.

International studies ${ }^{14,16}$ have described the impact of qualitative researches aiming to characterize human interactions, making the study of linguistic experiences and phenomena possible. With such perception, interviews were carried out using SPAA-C, seeking to promote the participation of professionals in the difficulties related to speech. The results have demonstrated how socio-emotional characteristics, social limitations and educational factors influence these children. The phenomenological qualitative analyses have indicated as main reports the frustration of the children and the effort of parents in the attempt to understand them. Therefore, it has been concluded that a successful communication depends on the ability 
of the speakers and listeners and on reciprocal support between them.

The study is justified by the lack of questionnaires in Brazil related to the impacts caused by SSD, particularly when it is considered that this sort of complementary assessment contributes to the attention given to each case/patient, helping with feedback to the speechlanguage pathologist, as well as for evaluating the need of a referral to a multi-professional team. In addition to that, the questionnaire proves to be an efficient tool that may, along with other tools and observations in the assessment process, contribute to a better understanding of the child's difficulties, so helping in the awareness and behavior of the family.

With this in mind, there is a hypothesis that SSD causes an impact on communicative, emotional, learning and social spheres. Furthermore, it is expected that there will be greater significance in the questionnaire answered by the children due to its closed-ended questions and the illustrative answer options.

Thus, the aim of this research was to verify the family's and the child's perception of the impact of the phonological type of SSD.

\section{METHODS}

This research has been properly registered at the Research Ethics Committee of the Federal University of Santa Maria and has been approved under the checking number 719.011. It is an exploratory qualitative-quantitative prospective research.

Sixty-four individuals took part in the study, thirtytwo of which were either parents or guardians and the other thirty-two were children previously diagnosed with phonological types of SSD. Nineteen of the children were boys and thirteen were girls, their age ranging from four years and one month to eight years and nine months. These children were either on the waiting list or being taken care of at the Speech-Language Pathology Service of the Higher Education Institution.

The children's parents and guardians signed an informed consent authorizing their participation in this research. The children themselves freely agreed to participate on the research, verbally acquiescing.

Finally, the researchers committed themselves to make public the collected data and results only in scientific environments, and to keep absolutely secret the participants' identity, as it has been made plain in the informed consent.

As for inclusion criteria, the children would have to show understanding of language in accordance with their age as well as auditory threshold previously assessed to be within normal range. Based on information provided by their relatives, children who presented anatomic or physiologic abnormalities in the speech production mechanism were excluded from the samples.

The procedures were initiated with a meeting which parents and guardians attended for the initial interview and signing of the informed consent. After that, the children underwent the following procedures.

Speech evaluation was carried out by means of a tool for assessing phonological awareness (INFONO, in Portuguese $)^{12}$, which was collected through recording of spontaneous naming. The INFONO is a piece of software that evaluates nineteen consonants of BP in the various syllable structures, plus the possible consonant clusters. Following the data collection, contrastive analysis was carried out; also, the severity of the phonological type of SSD was calculated based on the Percentage of Consonants Correct - Revised (PCC - R), proposed by Shriberg et al. (1997) ${ }^{16}$, which doesn't consider distortions made by children. Regarding the severity of the phonological type of SSD, it may be classified as: slight deviation (85-100\%), slightto-moderate deviation (65-85\%), severe-to-moderate deviation $(50-65 \%)$ and severe deviation $(<50 \%)^{17,18}$.

After having calculated the severity, the children were distributed in groups according to their severity. Seven children (five boys and two girls) were grouped together as having severe or severe-to-moderate deviation; they were classified as "Severe". The other twenty-five children (fourteen boys and eleven girls) presented either slight or slight-to-moderate deviation, and they were grouped together and classified as "Slight".

All the children were being assisted by the SpeechLanguage Pathology Service; therefore, assessments related to orofacial motor control and to hearing were carried out only in the cases which had no such evaluation data in their medical records.

The Speech Participation and Activity Assessment of Children (SPAA-C), proposed by McLeod $(2004)^{13}$, was translated into BP as "Avaliação da Participação e Atividade de Fala de Crianças". It was then translated back into English by two people proficient in English. Originally, SPAA-C adds up to eighty-two questions, divided into those for the children, their parents, brothers, friends, teachers and other close acquaintances. In this study, the questionnaire was applied only to the children and their parents or guardians, making 
use of forty-seven questions. The "Questions for the child" are those numbered 1 to 14 and 25 to 27 , in a total of seventeen open-ended questions, performed orally. There are also the ones numbered 15 to 24 , totaling ten, which are closed-ended multiple-choice questions. To these, the child answered whether he/ she felt "happy", "more or less", "sad", "other feeling" or "doesn't know". The "Questions for the parents" add up to twenty, to which open-ended oral answers were given, seeking for considerations and reflecting of the parents. It is important to point out that the interviews were made individually, while the children were in treatment or evaluation at the Service. All the interviews were recorded and then transcribed for analysis. The answers were inserted in an Excel spreadsheet and then exported to the $\mathrm{R}$ Environment for analysis.

The questions asked to the parents and children are found in Figure 1.

\begin{tabular}{|c|c|}
\hline \multicolumn{2}{|r|}{ QUESTIONS FOR THE PARENTS } \\
\hline \multicolumn{2}{|c|}{ Your child } \\
\hline Q1 & Tell me about your son/daughter. \\
\hline Q2 & What does your son/daughter enjoy doing? \\
\hline Q3 & What is important for your son/daughter and your family? \\
\hline Q4 & $\begin{array}{l}\text { What would be the weekly routine of activities? What would be the people your son/daughter would talk to in a } \\
\text { regular routine week? }\end{array}$ \\
\hline Q5 & Is he/she invited to play in other children's homes or invited to birthday parties? \\
\hline Q6 & Is there any specific thing that makes your son/daughter particularly sad or aggressive? \\
\hline \multicolumn{2}{|c|}{ Your son/daughter speech } \\
\hline Q7 & Describe your son's/daughter's speech. \\
\hline Q8 & $\begin{array}{l}\text { What difference do you notice regarding your son's/daughter's speech in comparison to their siblings' or friends' } \\
\text { speech, in relation to: }\end{array}$ \\
\hline Q8(a) & Amount of speech. \\
\hline Q8(b) & How he/she is understood. \\
\hline Q8(c) & Context and people whom he/she feels comfortable to speak with. \\
\hline Q8(d) & Context and people whom he/she feels uncomfortable to speak with. \\
\hline Q9 & When your son/daughter is not understood: \\
\hline Q9(a) & What does he/she do? \\
\hline Q9(b) & What do you do to help? \\
\hline Q10 & What is your son/daughter good enough at, that doesn't require him/her to speak properly? \\
\hline \multicolumn{2}{|c|}{ The impact of your son's/daughter's speech difficulty } \\
\hline Q11 & What is the greatest impact of your son's/daughter's speech difficulty at home and at school? \\
\hline Q12 & How does the speech difficulty limit him/her? \\
\hline Q13 & Has he/she ever been excluded from social situations because of speech? \\
\hline Q14 & What kind of things does your family do to assure that your son/daughter be socially included? \\
\hline Q15 & $\begin{array}{l}\text { How conscious/frustrated is he/she regarding his/her speech difficulty? Does he/she feel ashamed of his/her } \\
\text { speech? }\end{array}$ \\
\hline Q16 & $\begin{array}{l}\text { Have you noticed different levels of confidence and communication skills in situations like: at meals, at school, with } \\
\text { friends, with his/her grandparents or with other family members, during leisure and extracurricular activities (for } \\
\text { example, swimming classes...)? }\end{array}$ \\
\hline Q17 & How do other people react to your son/daughter? \\
\hline Q18 & What do other people say to you about your son's/daughter's speech? \\
\hline Q19 & Do you feel frustrated/ashamed of your son's/daughter's speech? \\
\hline Q20 & What goals would you like to reach regarding your son's/daughter's communication skills? \\
\hline
\end{tabular}




\begin{tabular}{|l|l|}
\hline \multicolumn{2}{|l|}{ QUESTIONS FOR THE CHILDREN } \\
\hline Q1 & What are your favorite activities? At home? At school/preschool? \\
\hline Q2 & What games/sports do you play? \\
\hline Q3 & What are you good at? \\
\hline Q4 & Whom do you like to play with? \\
\hline 25 & If your mom or dad said: "What do you want to do?", what would you answer and who would you take with you? \\
\hline Your friends & \\
\hline Q6 & Whom do you like to play with? \\
\hline Q7 & What's fun for you at school/preschool? \\
\hline Q8 & What's the best thing about school/preschool? \\
\hline Q9 & What's difficult for you at school/preschool? \\
\hline Q10 & Have you ever been provoked at school/preschool? \\
\hline Your talk (speech) \\
\hline Q11 & Whom do you like to talk to? \\
\hline Q12 & When do you like to talk to people? \\
\hline Q13 & When don't you like to talk to people? \\
\hline Q14 & Do you think your speech is different from that of the other children? \\
\hline Q15 & How do you feel when you talk? \\
\hline Q16 & How do you feel when you talk to your best friend? \\
\hline Q17 & How do you feel when you talk to your brother/sister? \\
\hline Q18 & How do you feel when you talk to your parents? \\
\hline Q19 & How do you feel when you talk to your teacher? \\
\hline Q20 & How do you feel when your teacher asks a question? \\
\hline Q21 & How do you feel when you speak to the whole class? \\
\hline Q22 & How do you feel when you play with children at school? \\
\hline Q23 & How do you feel when you play by yourself? \\
\hline Q24 & How do you feel when people don't understand what you say? \\
\hline Q25 & Has your speech ever bothered you? What do people say? \\
\hline Q26 & Do people often ask you to repeat what you've said? How does that make you feel? \\
\hline Q27 & $\begin{array}{l}\text { What do you do when someone doesn't understand you (for example: keep trying, change what you were going to } \\
\text { say, give up, get upset, etc.)? }\end{array}$ \\
\hline
\end{tabular}

\begin{tabular}{|c|c|c|c|c|c|}
\hline QUESTIONS & HAPPY & $\begin{array}{l}\text { IN THE } \\
\text { MIDDLE }\end{array}$ & SAD & $\begin{array}{l}\text { ANOTHER } \\
\text { FEELING }\end{array}$ & DONT KNOW \\
\hline $\begin{array}{l}15 \text { - How do you feel when you } \\
\text { speak? }\end{array}$ & (2) & $\theta$ & (2) & 0 & $?$ \\
\hline $\begin{array}{l}16 \text { - How do you feel when you talk } \\
\text { to your best triend? }\end{array}$ & (i) & $\theta$ & (2) & 0 & $?$ \\
\hline $\begin{array}{l}\text { 17- How do you feel when you talk } \\
\text { to your sisterbrother? }\end{array}$ & (i) & $\theta$ & (2) & 0 & $?$ \\
\hline $\begin{array}{l}18 \text { - How do you feel when you talk } \\
\text { to your parents? }\end{array}$ & (i) & $\theta$ & (2) & 0 & $?$ \\
\hline $\begin{array}{l}19 \text { - How do you feel when you talk } \\
\text { to your teacher? }\end{array}$ & (i) & $\theta$ & (2) & 0 & $?$ \\
\hline $\begin{array}{l}20 \text { - How do you feel when your } \\
\text { teacher asks you? }\end{array}$ & (ن) & $\theta$ & (2) & 0 & $?$ \\
\hline $\begin{array}{l}21 \text { - How do you feel when you talk } \\
\text { to whole class? }\end{array}$ & (i) & $\theta$ & (2) & 0 & $?$ \\
\hline $\begin{array}{l}22 \text { - How do } \\
\text { you feel when you play with your } \\
\text { classmatess children in wour school? }\end{array}$ & (:) & $\theta$ & (2) & 0 & $?$ \\
\hline $\begin{array}{l}23 \text { - How do you feel when you play } \\
\text { alone? }\end{array}$ & (i) & $\theta$ & (2) & 0 & $?$ \\
\hline $\begin{array}{l}\text { 24- How do you feel when people } \\
\text { do not understand what you say? }\end{array}$ & (:) & $\theta$ & $\theta$ & 0 & $?$ \\
\hline
\end{tabular}

Figure 1. Speech Participation and Activity Assessment of Children's Questionnaire 
The analysis of the research results was quantitative descriptive and inferential. The data were analyzed by means of $R$ software ( $R$ Core Team) ${ }^{19}$, more specifically with the help of packages intended for text data mining (SnowballC, tmandwordcloud2). In the sequence, the more frequently cited words were presented in frequency charts as well as through word cloud concept illustrations ${ }^{19}$, generated by the software. The most used keywords were put in evidence in the cloud by means of its position, color and size. After initially exploring the generated word clouds, words that were irrelevant in the context of the question asked were manually removed. Then, a second analysis of the word clouds was performed, aiming to avoid gender differentiation as words were stressed ("restless child", instead of "restless boy/girl") as well as the conjugation of verbs ("speak", instead of "speaks" or "spoke").

Finally, for each of the most used words in each question, the degree of association of that word with all other words in the same answer was presented. This statistics is a measure of association and it is equivalent to the association coefficient in a scale of zero to one, in which figures below 0.3 are considered as weak association, those between 0.3 and 0.7 as average association, and the ones above 0.7 as strong association. For most of the cases, the degree of association was verified to be between weak and average. It is important to mention that, in this study, the most relevant questions were selected in relation to the strong degree of association, the average association and the average association with aspects of speech.

The Fisher's exact test was used to carry on the analysis of questions 15 to 24 and of the "Slight" and "Severe" severity groups.

\section{RESULTS}

\section{Analyses of parents' answers to SPAA-C}

Thirty-two parents and guardians in all were interviewed. Their answers were charted and are represented in pictures, which have the different parts of the table referring to the questions used, numbered according to SPAAC. In Figure 2, as word clouds, the words that presented strong association were designated with the letter " $A$ ", and those with average association, with the letter " $\mathrm{B}$ ".

The pictures are presented according to the relation between frequency and association, in order to make the interpretation easier.

As seen in Figure 2, regarding the questions with strong association levels - A, in Q4 (parents), the most frequent answer was "school", which had strong association with "brother" as the answer. In Q8C (parents), the most frequent answer was "all of them", strongly associated with the answer "world". In Q8D (parents), the most frequent answer was "all of them", associated with "world" for the answer. Finally, in Q19 (parents) the answer "manner" was the most frequent, strongly associated with "none". As for the questions with average level of association - B, in Q1 (parents), "restless" was the most frequent answer, with average association with the answer "stubborn". In Q6 (parents), the answer "upset" was the most frequent and was averagely associated with the answers "whiner" and "reprove".

Parents' answers to the questionnaire with average association and relation to the child's speech have been illustrated in the word clouds, and are shown in Figure 3. 


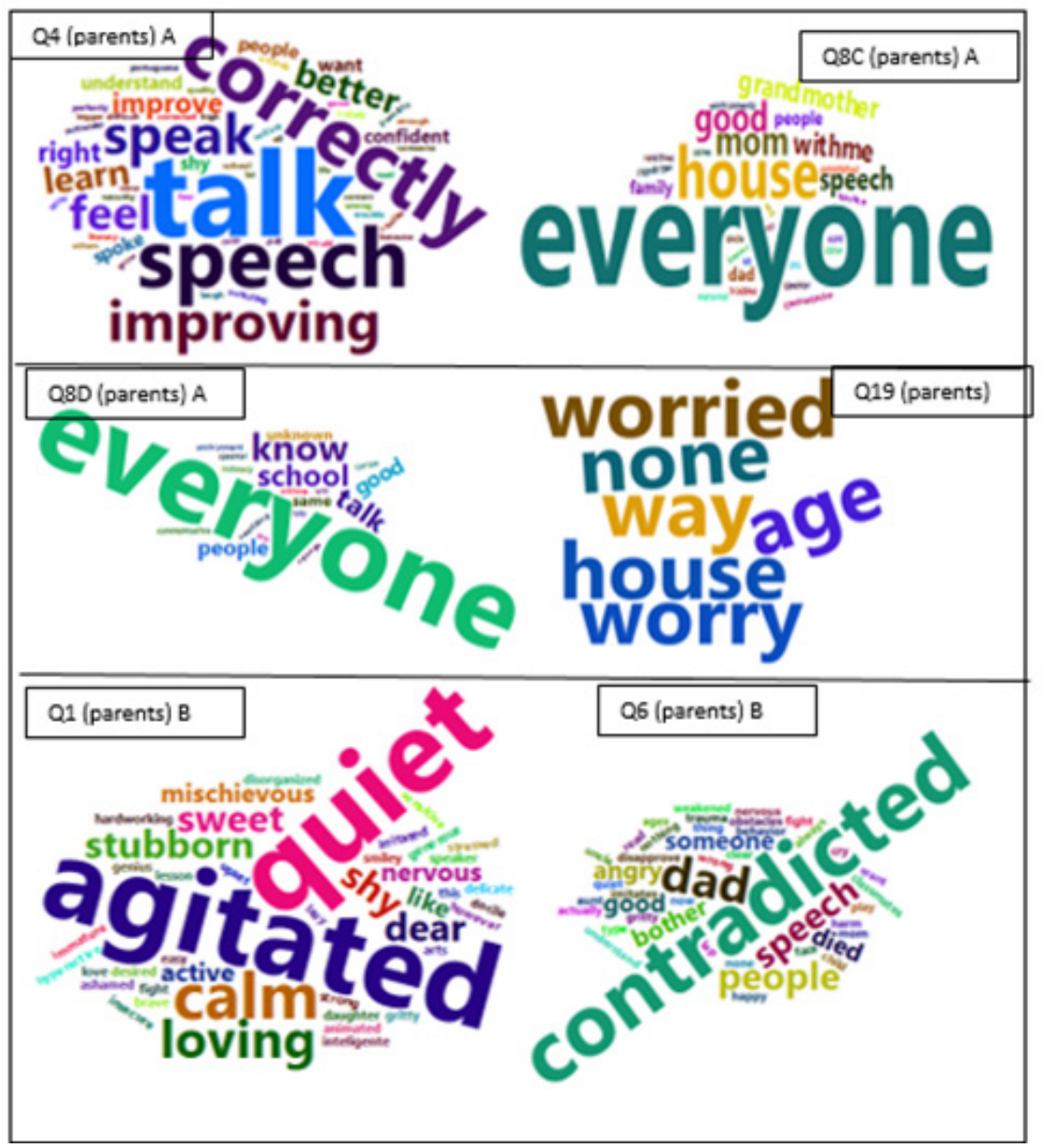

Figure 2. Answers with strong association $(A)$ and average association (B), for the parents

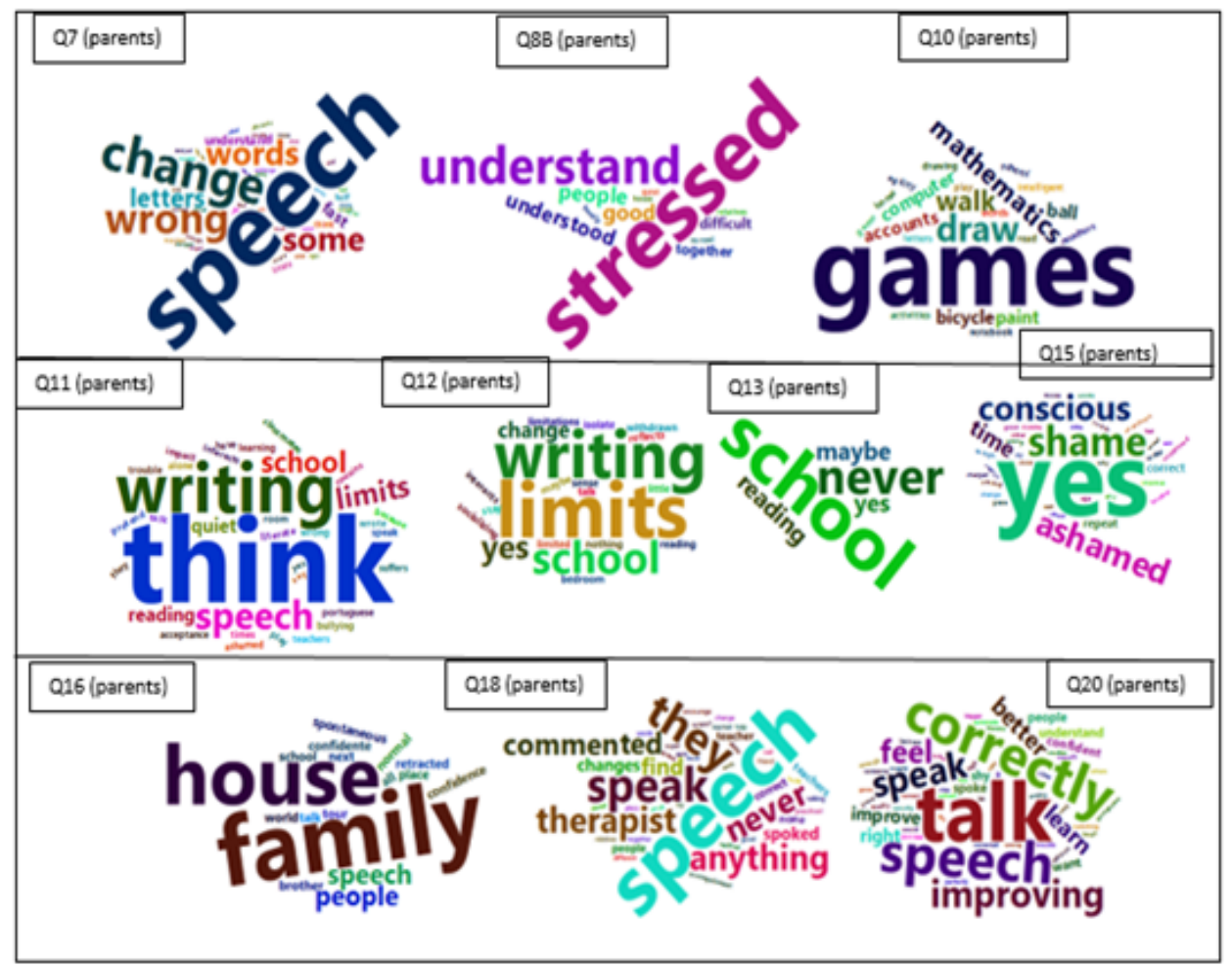

Figure 3. Answers with average association for the parents and relation with the child's speech 
Regarding Q7 (parents) the answer "speech" was the most frequent one and was associated with the words "delay, slow, think, normal and fast". As for Q8B (parents), "understood" was the most frequent word and there was evident association with "well". In Q10 (parents), the most frequent answer was "games", associated with the answers "computer, ball and video game". About Q11 (parents), the most frequent answer was "suppose", associated with "quiet, room and school". In Q12 (parents), the word "limits", was confirmed as the most frequent answer together with the answer "maybe, talk and hurt". In Q13 (parents), the most frequent answer was "school", associated with "yes, maybe and never". In Q15 (parents), the answer "yes" was the most frequent one, which obtained association with the answers "times, irritates and because". In Q16 (parents), the most frequent answer was "family" and it was associated with the answers "confident, school, withdrawn and spontaneous". In its turn, in Q18 (parents), the most frequent answer was "speech", and the associations were "speak, exchanges, delay, took, place, follow-up, relatives, motivate and different". Finally, in Q20 (parents), "speak" was the most frequent answer, associated with "learn and correctly".

\section{Analyses of the children's answers to SPAA-C}

The open-ended questions answered orally by the children did not present any level of strong association. Therefore, only the answers with average association and the answers with average association and relation to the child's speech are presented in Figures 4 and 5, respectively.

Among the questions with average association, in Q1 (children) the answer "play" was the most frequent one, which obtained association with "play, stay, quiet, dog, classmates and school”. In Q3 (children), the word "play" was the most frequent, and it was associated with "ball". In Q5 (children), the word "play" was the most frequent one and was associated with "alone, ride and bicycle". In Q6 (children), the most frequent word was "friends", which had association with "parents". Q8 (children) had "play" as the most frequent word, associated with "somebody, stories, read, park and counting". Finally, in Q9 (children), the most frequent answer was "read", associated with "know and alone".

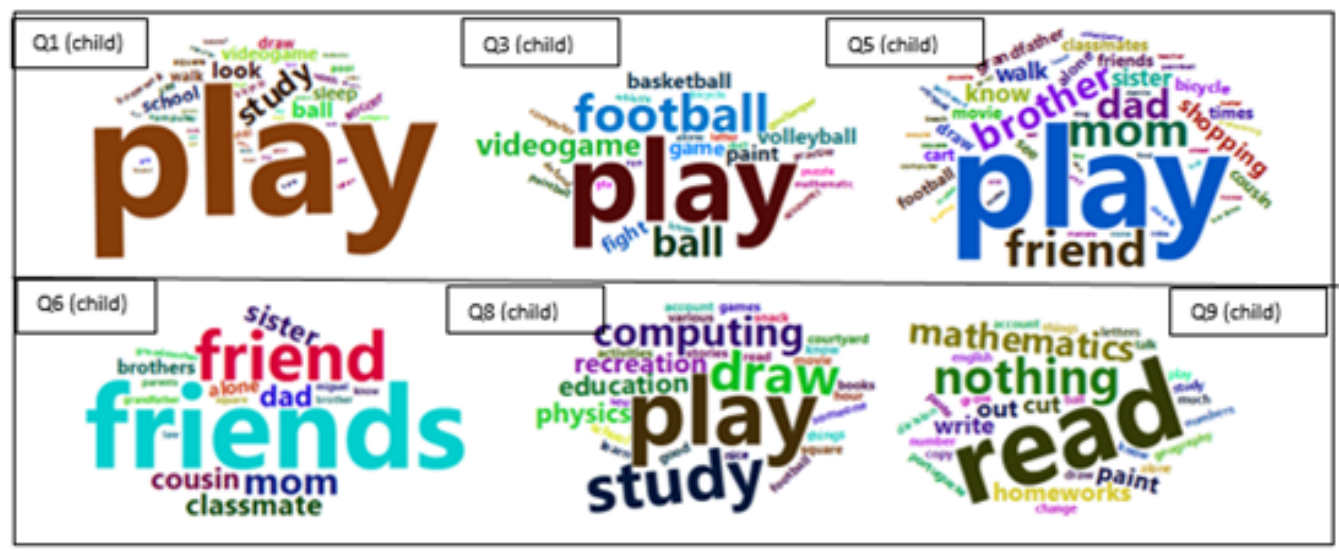

Figure 4. Answers with average association for the children

As for the questions that had average association and relation to the child's speech, in Q13 (children), the answer "sad" obtained average association with the answer "well". To Q25 (children), the most frequent answer was "yes", which obtained average association with the answers "feel and angry". Regarding Q26, the most frequent answer was "give up", with average association with the answer "shame". In Q27, the word "give up" obtained average association with the word "shame".

The analyses of the children's oral answers to the closed-ended questions are shown in Table 1. 


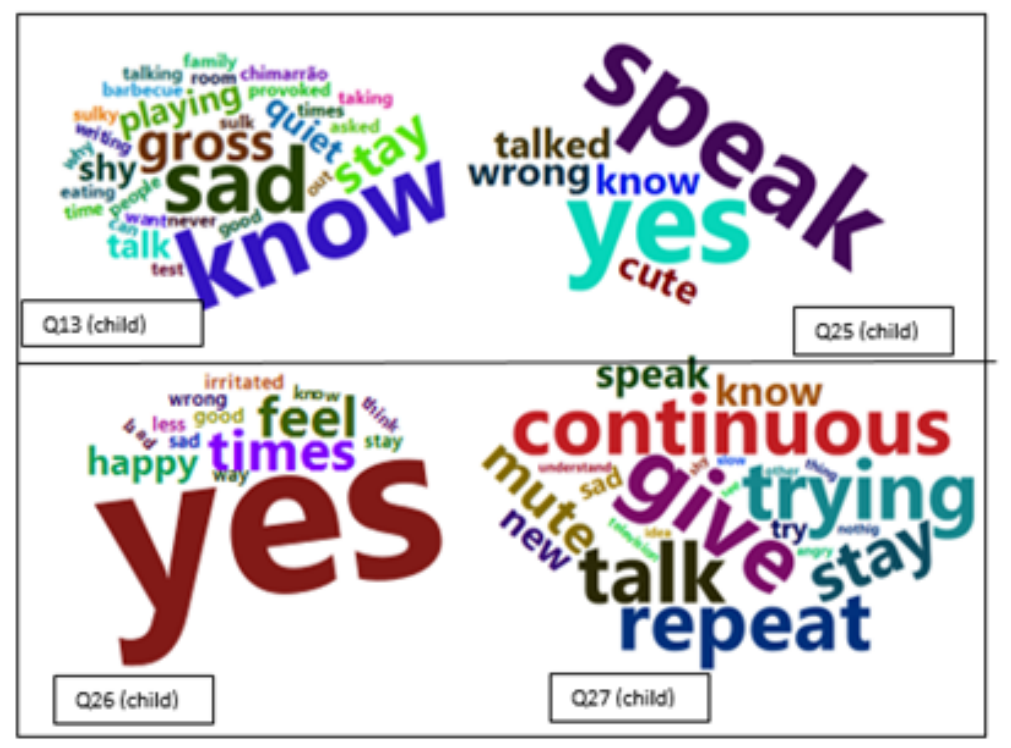

Figure 5. Answers with average association and relation with speech, for the children

Table 1. Distribution of children by severity group and answers to the multiple-choice questions (15 to 24).

\begin{tabular}{|c|c|c|c|c|c|c|c|}
\hline Deviation & No siblings & Happy & Average & Sad & Doesn't know & Other & Total \\
\hline Q15 & $(p=0.117)$ & & & & & & \\
\hline Severe & - & 2 & 3 & - & 2 & - & 7 \\
\hline Slight & - & 15 & 2 & 3 & 5 & - & 25 \\
\hline Q16 & $(p=0.424)$ & & & & & & \\
\hline Severe & - & 6 & - & - & - & 1 & 7 \\
\hline Slight & - & 22 & 2 & - & 1 & - & 25 \\
\hline Q17 & $(p=0.999)$ & & & & & & \\
\hline Severe & 4 & 2 & - & 1 & - & - & 7 \\
\hline $\begin{array}{c}\text { Slight } \\
\text { Q18 }\end{array}$ & $\begin{array}{c}11 \\
(p=0.404)\end{array}$ & 9 & 1 & 3 & - & 1 & 25 \\
\hline Severe & - & 3 & 1 & 2 & 1 & - & 7 \\
\hline Slight & - & 17 & 2 & 3 & 3 & - & 25 \\
\hline Q19 & $(p=0.176)$ & & & & & & \\
\hline Severe & - & 3 & 2 & 1 & 1 & - & 7 \\
\hline Slight & - & 17 & 7 & 1 & - & - & 25 \\
\hline Q20 & $(p=0.861)$ & & & & & & \\
\hline Severe & - & 2 & 1 & - & 3 & 1 & 7 \\
\hline Slight & - & 9 & 6 & 2 & 5 & 3 & 25 \\
\hline Q21 & $(p=0.241)$ & & & & & & \\
\hline Severe & - & 6 & - & - & 1 & - & 7 \\
\hline Slight & - & 10 & 7 & 3 & 2 & 3 & 25 \\
\hline Q22 & $(p=0.999)$ & & & & & & \\
\hline Severe & - & 6 & 1 & - & - & - & 7 \\
\hline Slight & - & 21 & 2 & 2 & - & - & 25 \\
\hline Q23 & $(p=0.472)$ & & & & & & \\
\hline Severe & - & 2 & 2 & 3 & - & - & 7 \\
\hline Slight & - & 4 & 3 & 17 & 1 & - & 25 \\
\hline Q24 & $(p=0.546)$ & & & & & & \\
\hline Severe & - & 1 & - & 4 & 2 & - & 7 \\
\hline Slight & - & 4 & 5 & 8 & 4 & 4 & 25 \\
\hline
\end{tabular}

Statistical test used - Fisher's exact test 
The results have not presented significant associations between the multiple-choice questions (Q15 to Q24) and the severity. However, some of the answers have shown a slight tendency to the association, namely, questions $15(p=0.117)$ and $19(p=0.176)$. In this regard, it is taken into consideration that there might be happier children whose SSD has a slight or slight-to-moderate level of severity, since these levels are closer to the understandable speech/communication, particularly the slight one. The term happy, used in this context, refers to one of the items present in the questionnaire.

\section{DISCUSSION}

Based on the results obtained through the answers with strong relation, it was possible to observe that in Q4 (parents), "going to school" was the most frequently mentioned response, which had association with "brother". This shows that going to school is a normal part of the children's daily routine, which is to be expected, since all the children in the research were in school age. In a study ${ }^{20}$, the authors state that an adequate routine makes possible for the children to build up their independence and autonomy, resulting in their insertion into society. Besides, a safe environment is important for the children to feel capable of dealing with their difficulties.

In Q8C and Q8D (parents), the most frequent answers were "everybody" to both questions, which suggest that some children have contexts and people with whom they feel comfortable to speak, unlike other ones who feel uncomfortable. In another study ${ }^{21}$, it has been verified that some children have an avoiding attitude towards the "other people", showing the child to be resistant concerning speech difficulties and worried about their being or not understood by other people.

Q19 (parents) has made it possible to notice that none of the parents are ashamed of their children's alteration in speech, since most of the answers were "manner", which was associated with "none". In spite of some studies ${ }^{21,22}$ pointing to the family as one of the influencing factors for the occurrence of Sound-Speech Disorders, in this work it was possible to observe that the parents seek to promote a mediating environment in such matters.

Regarding Q1 (parents), it was verified that most of the children show difficulties in a behavioral level, as the answer presented association with "stubborn". Besides, in Q6 (parents), "upset" was the most frequent answer and it obtained association with the answers "whiner and reprove", which demonstrates that speech impairment may also cause changes in the child's behavior. As for questions Q11 (parents), Q12 (parents) and Q13 (parents), it has also been possible to identify the above-mentioned situations, since the most frequent answers indicated that the children are limited because of their difficulties to speak. This leads to changes in their behavior, in the school and in their relationship with the other individuals. Children with disturbances in oral language usually have low school performance and develop feelings of frustration and low self-esteem. As a tendency, they may suffer from social isolation; this was reported by some parents, saying their children face school problems such as bullying. The victims of this sort of prejudice are usually timid and show difficulty in building a relationship with their mates ${ }^{10}$.

Q7 (parents) in its turn, which obtained "speech" as the most frequent answer and was associated with the words "delay", "slow", "think", "normal" and "fast", show that parents try to observe how their children speech works. One study pointed out that, concerning the relatives' perception of their children's speech difficulties, all of them mentioned some situation in which "the sounds were switched" in speech, even though it was hard to classify them in levels or degrees of difficulty of SSD ${ }^{11}$.

In relation to Q10 (parents), most of the parents reported that their children are good enough at games without the need of using speech properly, since in the question there was association with the answers "computer", "ball" and "video game". In these cases, it is important to stress that children prefer still activities, some of which are characteristic of isolation, such as the computer and the video game, since there are no involvement with other people.

In Q15 (parents) it was possible to verify that most of the children are aware of their speech difficulty, since "yes" was the most frequent answer. A study has revealed that children with alteration in speech may be aware of the phonological system considered as normal, for they are capable of reflecting upon the speech sounds, which in turn makes them conscious of their own deviation ${ }^{23,24}$.

In Q16 (parents), it was possible to notice "family" as the most frequent answer, associated with the answers "confident, school, withdrawn and spontaneous", making evident that family is the environment in which children feel the most comfortable to speak. 
The context provided by family and close friends normally offers a safe supportive environment where children can be themselves and take part in a typical childhood $^{16}$.

As for people's perception of alterations in speech, in Q18 (parents) the most frequent answer was "speech" and the associations were "speak, exchanges, delay, took, place, follow-up, relatives, motivate and different", showing that other people as well observe the aspects related to the functioning of speech in children, many of the times in a derogatory way. In a study carried out in Australia ${ }^{25}$, parents reported that, in public spaces, they had to protect their children in response to other people's reaction to the children's speech, mainly in regard to social aspects and emotional issues.

In Q20 (parents), "speak" was the most frequent answer, associated with "learn and correctly", indicating their parents desire for the children to develop speech appropriately and their interest in the therapeutic process. Two studies ${ }^{11,20}$ have pointed out it was possible to observe that parents feel as part of the therapeutic process. Their reports revealed even greater knowledge and understanding about the child's difficulties in speech, as well as their perception of improvements in the child's speech.

About the questions answered by the children, regarding their favorite activities, in Q1 (children) "play" was the most frequent answer. In the same line of thought, Q3 (children), Q5 (children) and Q8 (children) also refer to the activities the children enjoy to engage in, to which the most frequent answers were "play" and "play games". It is important to point out that playing is one of the most important elements in building up a child's symbolic and, consequently, for the development of the speech abilities. From the child's perspective, they play for the fun of it, even though it is the main factor of their growth in knowledge. While they play, children express themselves and exchange experiences as individuals belonging to a social group and a social context ${ }^{26}$.

In Q6 (children), referring to the people whom the child likes to play with, the most frequent answer was "friends" and it had association with "parents", which is to be expected because of their proximity to the child. This relationship is made evident in a study that refers to family and friends circles as providing a safe and supportive environment for the child ${ }^{16}$.

Finally, in Q9 (children), which concerns the activities they consider difficult to accomplish in school, the most frequent answer was "read", which was associated with "know and alone". Some children, due to alterations in speech, start their process of learning how to write before finishing the process of phonological acquisition. This may hinder the graphemephoneme decoding process, causing an impact in their learning process ${ }^{27}$.

As for Q13 (children), which refers to the moments when the children do not like to talk to people, the answer "sad" had constant association with the answer "well"; that is, children usually don't like to talk to other people when they're sad. This reaction is justified by the unintelligibility of the child's speech, making it hard for the other ones to understand him/her. A study has revealed that the understanding of the speech of children with SSD by the people in general is more hindered as compared to that of a speech-language pathologist, since these are trained to understand the speech of a child ${ }^{28}$.

Regarding Q25 (children), questioning whether the child has already been provoked because of how they speak and what people say about it, the most frequent answer was "yes", associated with the answers "feel and angry". This shows that most of the children have already been irritatingly provoked. Following the same line of thought, Q26 (children) and 27 (children) question whether people usually ask for the child to repeat what they had said, how they feel about it and how they react when they're not understood. To both questions, the most frequent answers were "yes and give up", being associated with the answer "shame". This makes reference to the child usually having to repeat what they had already said and to the shame they feel and/or the propensity to give up saying something. This once again shows that children with disturbances in oral language frequently develop feelings of frustration and low self-esteem, with a tendency to get isolated and to be shy, hindering the relationship with their mates ${ }^{11}$.

According to a study carried out with children with Speech Sound Disorder, social ties may be hindered by intelligibility of speech, which may also influence interpersonal events in general, with implications on how to build future social relations. For this reason, in most cases the change in social conduct and in psychological aspects of the child with phonological deviation is remarkable. This behavior was identified in the results, as it can be seen in Table 1, more specifically in Q24 (children), which shows that 38\% of the interviewed children feel sad when other people don't understand what they say ${ }^{29}$. 
It is important to stress that the results of this research show the need to inform healthcare professionals, educators and the population in general for them to be aware of SSD and its impact. Consequently, these professionals would be able to help promoting information about SSD, thus leading to better prevention in Primary Health Care and early intervention. This would bring benefits to the child and avoid some damage to oral communication and to other circumstances as well ${ }^{28}$.

Besides this, the health systems must be improved in relation to the ICF classification, for they are capable of promoting knowledge about health problems and pointing to its presence and severity; in the case of this study, the ones related to speech, both in individual and social level. Thus, it is possible to identify functionality, as described in the ICF, both in relation to health issues and to illnesses and disorders.

Not less important are the speech issues in this context, as the phonological ones made evident in this research, which are useful for considering the importance of early intervention. Teamwork is required in order to gather information that would promote health awareness among the population in general. This would enable children and relatives to find treatment in accordance with their needs, considering also environmental and social influences ${ }^{30,31}$.

Therefore, the use of questionnaires in clinic and academic routine and in health promoting campaigns is beneficial for this population, with impact on communication issues and, specifically, in the SSD.

Furthermore, as a limitation to this study, it must be pointed out that the children that were undergoing speech-language pathology treatment where this research was carried out, even those that were in the beginning of the treatment, could receive further information related to speech and its disorders.

\section{CONCLUSION}

Based on this study, it has been concluded that parents are aware both of the impact caused by the phonological type of SSD and the difficulties faced by the children regarding interpersonal relationships, emotional state and school problems.

The study has pointed out that children notice the impact of SSD and that unfamiliar environments are more likely to make them get isolated or develop feelings of frustration, shyness and low self-esteem. These factors hamper relationship with other people, hindering the effectiveness of oral communication.

\section{REFERENCES}

1. Crestani $A H$, Moraes AB, Souza APR. Association analysis between child development risks and children early speech production between 13 and 16 months. Rev. CEFAC. 2015;17(1):69-6.

2. Andrade CRF. Prevalência das desordens idiopáticas da fala e da linguagem em crianças de um a onze anos de idade. Rev Saúde Pública. 1997;31(5):495-501.

3. Ceron MI, Gubiani MB, Oliveira CR, Gubiani MB, Keske-Soares M. Prevalence of phonological disorders and phonological processes in typical and atypical phonological development. CODAS. 2017;29(3):1-9.

4. Newmeyer AJ, Grether S, Grasha C. Fine motor function and oral-motor skills in preschool-age children with speech sound disorders. Clinical Pediatrics. 2007;46(2):604-11.

5. Brancalioni AR, Keske-Soares M. Phonological disorders treatment effect with a stimulability and segment complexity strata model with speech intervention software (SIFALA). Rev. CEFAC. 2016;18(1):298-08.

6. Namasivayam AK, Pukonen M, Goshulak D, Yu VY, Kadis DS, Kroll R et al. Relationship between speech motor control and speech intelligibility in children with speech sound disorders. J Commun Dis. 2013;46(3):264-80.

7. Strand EA, Mccauley RJ, Weigand SD, Stoeckel RE, Baas BS. A motor speech assessment for children with severe speech disorders: reliability and validity evidence. J Speech Lang Hear Res. 2013;56(2):505-20.

8. Gubiani MB, Keske-Soares M. Phonological evolution of children with speech disorders submitted to different therapeutic approaches. Rev. CEFAC. 2014;16(2):663-71.

9. Giacchini V, Mota HB, Mezzomo CL. The details in the therapeutic process to the consonant clusters acquisition in the speech of children with phonological disorder. Rev. CEFAC. 2015;17(1):17-26.

10. Pagliarin KC, Brancalioni AR, Keske-Soares $M$, Souza APR. Relação entre gravidade do desvio fonológico e fatores familiares. Rev. CEFAC. 2011;13(3):414-27.

11. Melo RM, Backes FT, Mota HB. Perceptions of parents/guardians of children with phonological disorders about the phonological disorders and the speech therapy. Rev. CEFAC. 2015;17(6):1802-13. 
12. Ceron MI. Instrumento de avaliação fonológica (INFONO): desenvolvimento e estudos psicométricos [tese]. Santa Maria (RS): Universidade Federal de Santa Maria, Curso de Doutorado em Distúrbios da Comunicação Humana; 2015.

13. McLeod S. Speech pathologists' application of the ICF to children with speech impairment. Adv Speech Lang Pathol. 2004;6(1):75-81.

14. McComarck J, McLeod S, Mcallister L, Harrison LJ. My speech problem, your listening problem, and my frustration: the experience of living with childhood speech impairment. Lang Speech, Hea Serv Schools. 2010;41(4):379-92.

15. World Health Organization. International Classification of Functioning, Disability, and Health: Children \& Youth Version: ICF-CY. World Health Organization, 2007.

16. McLeod S, Daniel G, Barr J. "When he's around his brothers ... he's not so quiet": The private and public worlds of school-aged children with speech sound disorder. J Commun Dis. 2012;46(1):70-83.

17. Shriberg LD, Austin D, Lewis BA, Mcsweeny JL, Wilson DL. The percentage of consonants corrects (PCC) metric: extensions and reability data. J Speech Lang Hear Res. 1997;40(4):708-22.

18. Shriberg LD, Kwiatkowski J. Phonological disorders I: a diagnostic classification system. J Speech Lang Hear Res. 1982;47(3):226-41.

19. R Core Team. R: a language and environment for statistical computing. R Foundation for Statistical Computing, Vienna, Austria; 2017.

20. Pires ARS, Moreno GL. Rotina e escola infantil: organizando o cotidiano de crianças de 0 a 5 anos. SIPD/CÂNTEDRA UNESCO. Londrina: PUCPR, 2015.

21. Cervi T, Keske-Soares M, Drugg AMS. A posição refratária em crianças com desvio fonológico analisada por meio dos contos de fadas. Psicologia em Estudo. 2015;20(2):213-24.

22. Cervi T, Keske-Soares M, Drugg AMS. Implicações do discurso parental no desvio fonológico. Estudos de Psicologia. 2016;33(4):689-97.

23. Dias RF, Mota HB, Mezzomo CL. A consciência fonológica e a consciência do próprio desvio de fala nas diferentes gravidades do desvio fonológico. Rev. CEFAC. 2009;11(4):561-70.

24. Santos MJ, Barrera SD. Impacto do treino em habilidades de consiência fonológica na escrita de pré-escolares. Psicol Esc e Educ. 2017;21(1):93-02.
25. Daniel GR, McLeod S. Children with speech sound disorders at school: challenges for children, parents and teachers. Austr Jour of Teach Educ. 2017;42(2):81-6

26. Biazotto L. A brincadeira e o desenvolvimento da criança na Educação Infantil [Monografia]. Medianeira (PR): Universidade Tecnológica Federal do Paraná; 2014.

27. Cardoso-Martins C. A consciência fonológica e a aprendizagem inicial da leitura e da escrita. Estud. pesqui. psicol. 2013;13(2):460-79.

28. Rosado IM, Donicht G, Simoni SN, Pagliarin KC, Keske-Soares M. Perception of the intelligibility and severity level of speech sound disorders by speech language pathologists and non-professionals. Rev. CEFAC.2016;19(2):233-41.

29. Ribas LP, Sant'anna BS, Da Silva KZ. Variáveis facilitadores na produção de palavras: dados de fala de crianças com Transtorno Fonológico. Domínios da Lingu@gem. 2015;9(5):288-08.

30. Ruaro JA, Ruaro MB, Souza DE, Fréz AR, Guerra RO. An overview and profile of the ICF's use in Brazil - a decade of history. Rev Bras Fisioter. 2012;16(6):454-62.

31. Finger ME, Cieza A, Stoll J, Stucki G, Huber EO. Identification of intervention categories for physical therapy, based on the international classification of functioning, disability and health: a Delphi exercise. Phys Ther. 2006;86(9):1203-20. 